\title{
BIOMECHANICAL ASPECTS OF BLUNT AND PENENTRATING HEAD INJURIES
}

\author{
Narayan Yoganandan, PhD, Frank. A. Pintar, PhD, Jiangyue Zhang, PhD, \\ Thomas A. Gennarelli, MD, and Nathaniel Beuse*, MS \\ Department of Neurosurgery, Medical College of Wisconsin, 9200 West Wisconsin Avenue, \\ Milwaukee, WI, 53226 USA \\ *US DOT, NHTSA, Washington, DC, USA \\ Phone : 414-384-3453, fax : 414-384-3493, e-mail :yoga@mcw.edu
}

\begin{abstract}
The objective of this presentation is to discuss certain biomechanical aspects of head injuries due to blunt and penetrating impacts. Emphasis is given to fundamental data leading to injury criteria used in the United States (US) regulations for motor vehicle safety. Full-scale and component tests done under US Federal Motor Vehicle Safety Standards (FMVSS) are described. In addition, results providing occupant safety and vehicle crashworthiness information to the consumer from frontal and lateral impact crash tests are discussed with an emphasis on head injury assessment and mitigation. Recent advancements are presented in angular acceleration thresholds for quantifying brain trauma. In the area of penetrating impact, newer experimental techniques are described for a better understanding of head injury secondary to penetrating impacts, with specific reference to the civilian population.
\end{abstract}

Key words: Head injury criteria, Federal Motor Vehicle Safety Standards (FMVSS), brain injury, skull fracture, penetrating trauma, linear and rotational accelerations

\section{PURPOSE}

Head injuries to the civilian population occur due to blunt or penetrating impacts. Motor vehicle crashes are a major source of blunt impact-induced head injuries. Biomechanical techniques used to establish injury criteria are helpful for assessing occupant safety and design user-friendly vehicular components. This presentation describes developments in this area along with current US standards. In the area of penetrating head trauma, a significant majority of the literature is from the military domain $[1,2]$. Recently, the focus has shifted toward the civilian domain, and because of 
technological improvements, it is possible to conduct tests to describe biomechanical aspects of injury from this type of external insult.

\section{BLUNT IMPACT - FUNDAMENTAL DATA USED IN INJURY ASSESSMENT}

Quantifications of head injuries were reported in the 1930-60 literature, although limited fundamental biomechanical studies were conducted earlier [3-7]. Linear and angular accelerations were considered governing variables to describe mechanisms of trauma and define tolerance limits $[8,9]$. Translational acceleration-time histories were related to skull fracture, using tests from four isolated embalmed cadaver heads and two full-body cadavers subjected to forehead impacts on flat unyielding surfaces. The specimens were dropped from predetermined heights and resulting linear accelerations were recorded at the occiput using an accelerometer. Pulses were of short duration because of the rigid end condition at the instant of impact. Association of linear skull fracture with brain injury, i.e., concussion $(80 \%$ correlation from clinical cases) was based on previous studies [3,5]. Peak accelerations were used from three isolated and two intact whole-body cadaver tests, and mean acceleration data was used from the other isolated head to develop the original tolerance curve that had durations of up to 6 msec [8]. This curve and corrected data are shown in figure 1. Animal experiments were used to extrapolate to longer duration acceleration-time impacts. The final response, termed Wayne State University Tolerance Curve (WSTC) using effective accelerations as the ordinate, was obtained from animal, volunteer, human cadaver, and clinical research data $[10,11]$. While WSTC is applicable to the adult population, no efforts were made to develop age-dependent tolerance curves. Versace in 1971 argued that because WSTC curve was developed for average accelerations, comparisons should be made using the mean pulse of interest [12]. He proposed the head injury criterion (HIC), which was modified by NHTSA to provide a better comparison to longer duration human volunteer data [12,13]. This criterion was adopted by FMVSS in 1972 and is still used worldwide for head injury assessment in various areas of impact biomechanics [14]. The criterion is given in equation (1).

$$
H I C=\left[\frac{1}{t_{2}-t_{1}} \int_{t_{1}}^{t_{2}} a(t) d t\right]^{2.5}\left(t_{2}-t_{1}\right)
$$


Where $t_{2}$ and $t_{1}$, arbitrary final and initial times during the acceleration pulse, are chosen to maximize $\mathrm{HIC}$ and $\mathrm{a}(\mathrm{t})$ is the resultant acceleration at the center of gravity of the head. NHTSA chose a value of 1000 as the threshold in 1972. In October 1986, the interval over which HIC was computed was limited to $36 \mathrm{msec}\left(\mathrm{HIC}_{36}\right)$ with the same threshold of 1000 for the $50^{\text {th }}$ percentile Hybrid III anthropomorphic dummy. From a theoretical perspective, Backaitis stated that "the HIC formulation contains the peak power term or the rate of change of energy as seen by the head during the impact process" [15]. Eppinger interpreted HIC "as a measure of the change of specific kinetic energy modulated by the square root of the average acceleration over the time interval," and further remarked that, "if the 2.5 power in HIC equation were instead 2, the function would represent the peak average specific power delivered to the head [16]."

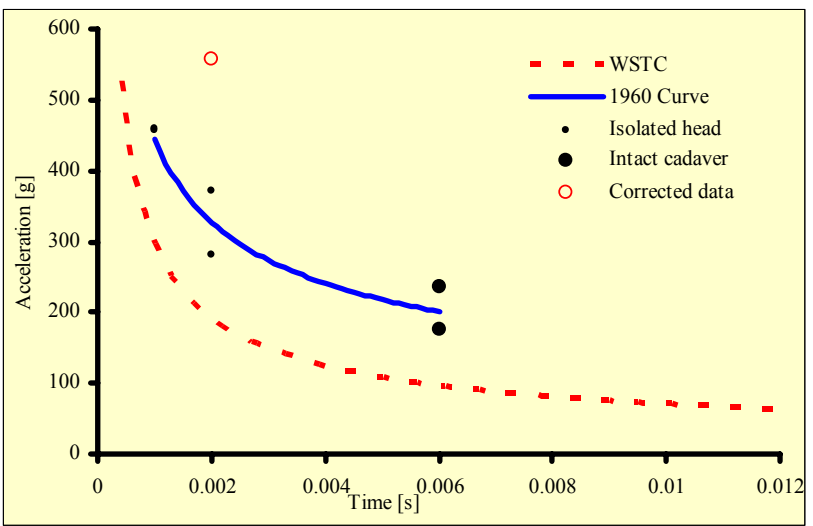

Figure 1. Acceleration responses from embalmed human cadaver tests and the original and revised tolerance curves. The $280 \mathrm{~g}$ data (at $0.002 \mathrm{sec}$, below the $1960 \mathrm{curve}$ ) was incorrectly plotted in the original publication [8]; corrected data is shown, open circle $(0.001 \mathrm{sec}, 557 \mathrm{~g})$.

\subsection{Adult occupant protection in frontal impact - FMVSS 208}

The principal purpose of the standard is to decrease the number of injuries and fatalities by specifying crashworthiness of vehicles in terms of biomechanical variables measured in dummies tested in simulated environments. The federalized Hybrid III dummy is the anthropomorphic test device. The FMVSS 208 standard specifies the injury metric in terms of HIC for different dummies for head impact protection. The frontal impact standard calls for full-scale vehicle-to-barrier tests at a velocity of $48 \mathrm{~km} / \mathrm{h}$ and $40 \mathrm{~km} / \mathrm{h}$ with outboard belted and unbelted dummies in the front seat for the $50^{\text {th }}$ percentile male dummy. While the same fixed rigid barrier tests are specified for the $5^{\text {th }}$ percentile female dummy, tests include an additional 
$40 \%$ left offset frontal deformable barrier test with belted driver and passenger dummies for the $5^{\text {th }}$ percentile female anthropometry (Figure 2). In the case of the unbelted test with the $50^{\text {th }}$ percentile adult male dummy, the vehicle is required to impact the rigid fixed barrier perpendicular to its line of travel and at any angle up to 30 degrees in either direction from the traveling line. In all tests and for both anthropometries (except offset test), the impact is always perpendicular to the path of the vehicle. For certain vehicles, an alternative unbelted test is done to evaluate airbags by sled testing at $48 \mathrm{~km} / \mathrm{h}$ such that the sled acceleration falls within the corridors shown in figure 3. HIC, determined using the resultant acceleration at the center of gravity of the dummy head, is computed over a $15-\mathrm{msec}$ interval. The injury criterion is based on linear head acceleration data gathered for a period of $300 \mathrm{msec}$ after the vehicle strikes the rigid barrier. HIC limit is chosen as 700 for both adult anthropometries, with no gender bias. For child dummies, $\mathrm{HIC}_{15}$ values are as follows: 12-month-old CRABI (Child Dummy AirBag Interaction) is 390, 3-year-old is 570, and 6-year-old is 700. It should be noted that the $95^{\text {th }}$ percentile dummy is not specifically included in the current 208 standards, although the HIC value of 700 was suggested during rulemaking processes.

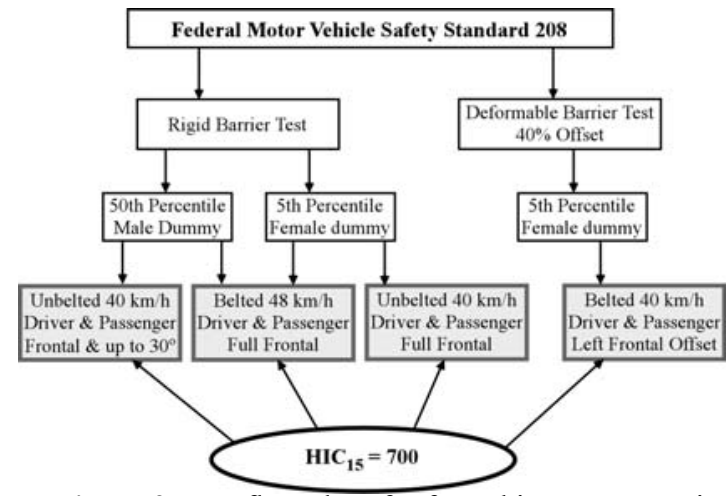

Figure 2. Test flow chart for frontal impact protection.

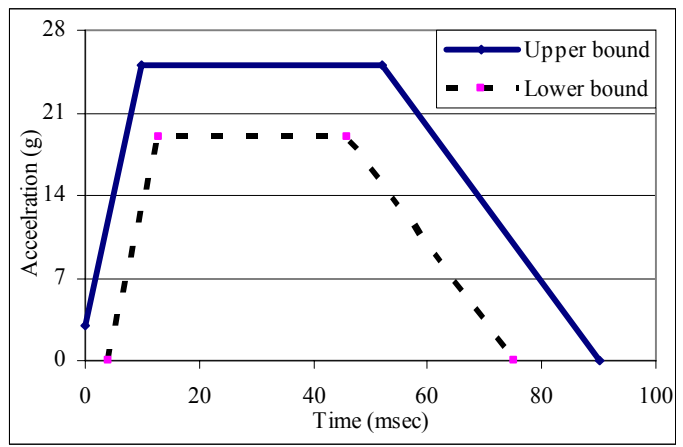

Figure 3. Deceleration pulse corridors for alternative sled tests with unbelted dummies. 
The New Car Assessment Program (NCAP) referred to as consumer information tests for relative crashworthiness of vehicles, was initiated by NHTSA in 1978 [17]. The ultimate goal of NCAP is to improve safety by providing market incentives for vehicle manufacturers to voluntarily implement improved crashworthiness in vehicles, rather than through only regulations, i.e., compliance tests such as 208 and 214 standards. For frontal impacts, procedures similar to 208 are followed with the speed raised from 48 to $56 \mathrm{~km} / \mathrm{h}$. This increased speed differentiates the performance of vehicles as the energy in the NCAP test is $36 \%$ higher than the compliance $48 \mathrm{~km} / \mathrm{h}$ test. Another measure of severity is the change in velocity $(\Delta \mathrm{V})$ of the occupant: $64 \mathrm{~km} / \mathrm{h}$ (accounting for rebound) in the NCAP compared to $53 \mathrm{~km} / \mathrm{h}$ in the compliance test. The NCAP currently computes HIC over a 36 -msec interval compared to the 15 -msec interval used in 208. However, in a recent Request for Comments (RFC) regarding the frontal program, NHTSA gave indication of its intent to begin using $\mathrm{HIC}_{15}$ as part of any potential upgrade. By combining injury numbers from the head and chest, a star-rating and a probability of injury are computed (Table 1). NHTSA published an RFC for establishing a high-speed regulation in 2001; it does not have a high-speed frontal offset test in the current standards. Figure 4 shows the probability of injury (AIS 4+) as a function of HIC. The head injury risk from real-world data (National Automotive Sampling System, NASS database) at the two speeds falls on the probability curve.

Table 1: Star-rating in rigid barrier frontal impact NCAP test

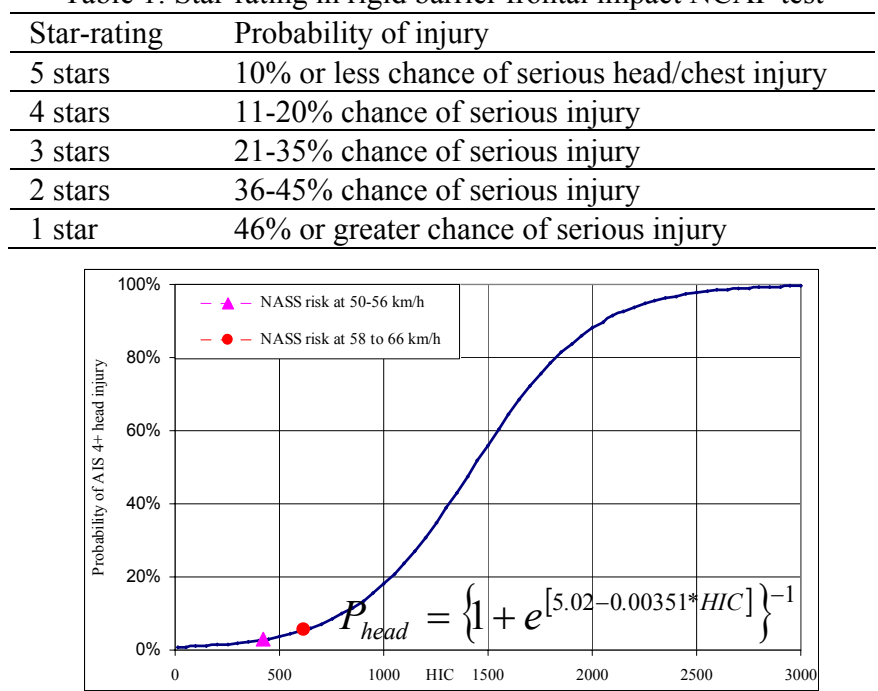

Figure 4. Probability of head injury as measured by HIC for MAIS $\geq 4$ in frontal impacts. Solid circle and triangular symbols show the risk of head injury based on NASS analyses. 


\subsection{Occupant protection in side impact - FMVSS 214}

The FMVSS 214 standard uses the side impact dummy (SID) designed for lateral impact crashworthiness evaluations. However, a newer dummy, ES2re, is being considered for future crashworthiness tests because of its enhanced biofidelity compared to SID [18]. Specific limits for head injury assessment do not exist in the current version; thoracic and pelvic regions are covered by respective injury metrics. Like the frontal NCAP, the lateral impact test, LINCAP, uses a higher speed for the moving deformable barrier $(62 \mathrm{~km} / \mathrm{h}$ instead of $54 \mathrm{~km} / \mathrm{h}$ in the compliance 214$)$ test. These tests also use a star-rating, but the probabilities are different because the side starrating is calculated only from injury metrics recorded in the chest/torso compared to the frontal impact that uses metrics from both the head and chest. However, since April 2002, NHTSA has noted safety concerns not reflected in the star-rating. One of those is specific to head injuries in LINCAP crash test. A safety concern remark is introduced informing the consumer about the potential for head injury in tests with $\mathrm{HIC}_{36}$ exceeding 1000. It should be noted that the same threshold of 1000 is chosen based on the FMVSS 201 pole test. Figure 5 shows the warning scheme that incorporates head injury measure in LINCAP tests, although probabilities are not attached with respect to specific HIC values.

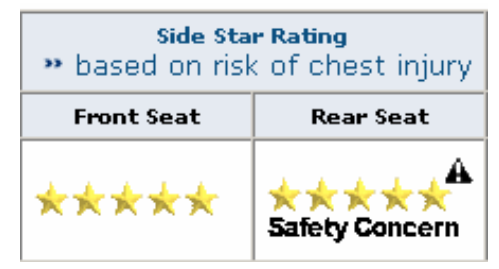

Figure 5. Rating scheme used in lateral impact NCAP tests wherein a warning indicating a higher likelihood of head injury is noted if the test results in a $\mathrm{HIC}_{36}$ value exceeding 1000 .

\subsection{Child occupant protection in frontal impact - FMVSS 213}

The FMVSS 213 standard focuses on child restraint systems. Unlike other standards, different dummies are used representing the growing anthropometric characteristics of the human child; table 2 shows specific dummies used for tests. Similar to 208, this standard also uses HIC although the time interval is $36 \mathrm{msec}$, and the threshold value of 1000 is independent of dummy age. Specifically, depending on the type of restraint, newborn, 9month old, 12-month, 3- and/or 6-year old dummies are subjected to a $\Delta \mathrm{V}$ of $48 \mathrm{~km} / \mathrm{h}$ in a sled environment. The newborn and 9-month old are not 
instrumented. The characteristic pulse shown in figure 6 has a peak acceleration of $23.5 \mathrm{~g}$ at $20 \mathrm{~ms}$. For child seats manufactured after August 1, 2005, NHTSA added upper and lower bounds to the pulse (Figure 7).

Table 2: FMVSS 213. Parentheses refer to the subpart specification of the part 572 dummy.

\begin{tabular}{lcl}
\hline Weight $(\mathrm{kg})$ & Height $(\mathrm{mm})$ & $\begin{array}{l}\text { Dummy to be used in child seats } \\
\text { manufactured before August 1, 2005 }\end{array}$ \\
\hline$\leq 5$ & $\leq 650 \mathrm{~mm}$ & Newborn (part 572 K) \\
\hline$>5$ and $\leq 10$ & $>650$ and $\leq 850$ & Newborn $(\mathrm{K})$ and 9-month-old $(\mathrm{J})$ \\
\hline$>10$ and $\leq 18$ & $>850$ and $\leq 1100$ & 9-month-old $(\mathrm{J})$ and 3-year-old $(\mathrm{C})$ \\
\hline$>18$ & $>1100$ & 6-year-old (I) \\
\hline Weight $(\mathrm{kg})$ & Height $(\mathrm{mm})$ & $\begin{array}{l}\text { Dummy to be used in child seats } \\
\text { manufactured on or after August 1, 2005 }\end{array}$ \\
\hline$\leq 5$ & $\leq 650 \mathrm{~mm}$ & Newborn (part 572 K) \\
\hline$>5$ and $\leq 10$ & $>650$ and $\leq 850$ & Newborn (K) and 12-month-old (R) \\
\hline$>10$ and $\leq 18$ & $>850$ and $\leq 1100$ & 12-month-old (R) and 3-year-old (P) \\
\hline$>18$ & $>1100$ & 6-year-old (N) \\
\hline$>22.7$ & $>1100$ & N dummy weighted to 28.2 kg \\
\hline
\end{tabular}

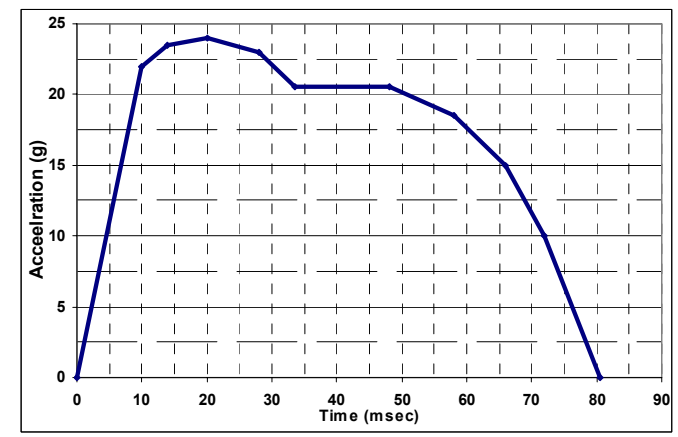

Figure 6. Acceleration-time history according to FMVSS 213 for vehicles manufactured before August 1, 2005.

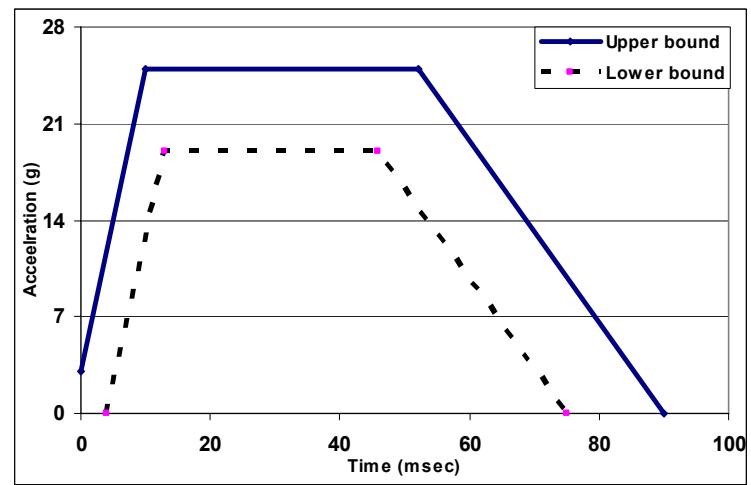

Figure 7. Acceleration-time history according to FMVSS 213 for vehicles manufactured on or after August 1, 2005. 


\subsection{Occupant protection in interior impact - FMVSS 201}

The FMVSS 201 standard has two parts. One part focuses on interior structures (A- and B-pillars and instrument panels) and uses HIC as the injury metric, with a different time limit for its computation, using a headform for testing. The other part is an optional test for dynamically deployed head protection systems and uses a pole test. For the head-form test, a 6.8 $\mathrm{kg}, 165-\mathrm{mm}$ diameter, free motion head-form impacts various points inside the vehicle with a velocity of $24 \mathrm{~km} / \mathrm{h}$. For a vehicle to pass, the deceleration of the head cannot exceed $80 \mathrm{~g}$ for a time period of $3 \mathrm{~ms}$. For evaluating dynamically deployed head protection systems, tests are done using a SID instrumented with a Hybrid III anthropomorphic head and neck and impacting the side of a full vehicle instrumented with a 254-mm diameter stationary rigid pole at a velocity between 24 and $29 \mathrm{~km} / \mathrm{h}$. The performance criterion is $\mathrm{HIC}_{36}$ threshold of 1000 . Injury criteria formula for the free motion head-form is given in equation 2.

$$
H I C=0.75446\left(\text { free motion head-form HIC } \mathrm{H}_{36}\right)+166.4<1000
$$

\subsection{Angular acceleration in head injury}

As indicated earlier, rotational accelerations have been implicated as a mechanism of injury since the 1940s $[9,19]$. In a series of publications, Genenralli and co-workers studied the effects of pure angular acceleration, i.e., without direct impact to the head, on brain injuries [20-24]. Their exhaustive research using subhuman primates and physical models led to the development of rotational acceleration thresholds for varying levels of brain injury including concussion, diffuse axonal injury (DAI), and subdural hematoma. More recently, Genneralli et al. synthesized these data and proposed angular acceleration thresholds for diffuse brain injuries as a linear function of varying severities (equation $3, \mathrm{R}^{2}=0.99$ ), described by the Abbreviated Injury Scale $[25,26]$.

$$
\ddot{\omega}=2.88 * A I S
$$

where, $\ddot{\omega}$ is the rotational acceleration $\left(\mathrm{krad} / \mathrm{sec}^{2}\right)$ and AIS represents the injury severity values in the length of unconsciousness section according to AIS 1998 version. Using descriptors adapted from literature (Table 3) and the above equation, relationships between various grades of brain injury and AIS were derived (Figure 8). The proposed $10 \%$ and $20 \%$ decrease in

tolerance due to the adverse effect of the epsilon 4 (e4) allele of the apoE 
genotype is also included in the figure. The profound adverse effect of the epsilon 4 allele of apoE on injury severity and outcome may reflect many factors including biomechanical changes in neuron or astrocyte cell membranes in the brain, and therefore, this genetic characteristic may affect brain injury tolerance [26].

Table 3: Diffuse brain injury categories. Concussion grades are according to ref ([27]).

\begin{tabular}{lccl}
\hline Description & AIS & $\begin{array}{l}\text { Concussion } \\
\text { grade }\end{array}$ & Loss of consciousness \\
\hline Mild concussion & 1 & 1 to 3 & None \\
\hline Classical concussion & 2 & 4 & Less than 1 hour \\
\hline Severe concussion & 3 & 4 & $1-6$ hours \\
\hline Mild diffuse axonal injury & 4 & 5 & $6-24$ hours \\
\hline Moderate diffuse axonal injury & 5 & 5 & $>24$ hours, no brain abnormality \\
\hline Severe diffuse axonal injury & 5 & 5 & $>24$ hr, decerebration/decortication \\
\hline
\end{tabular}

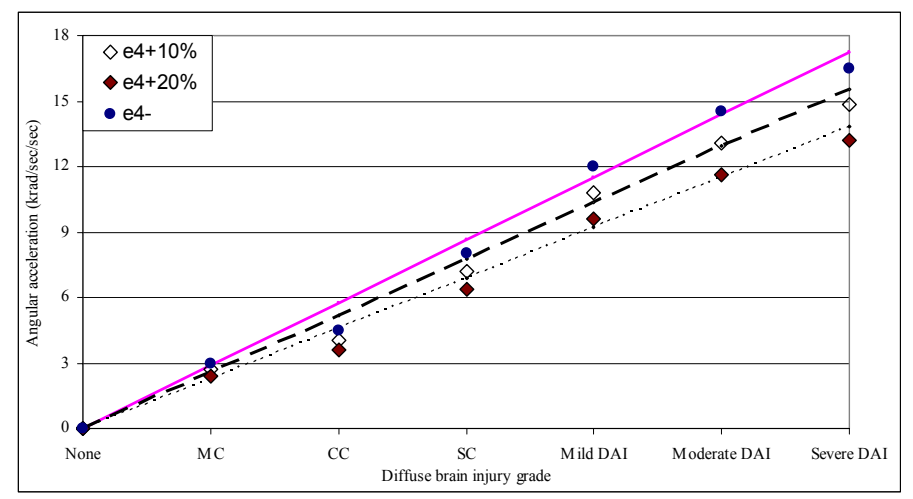

Figure 8. Angular acceleration ( $\mathrm{krad} / \mathrm{sec} / \mathrm{sec})$ as function of diffuse brain injury severity; e4- represents the normal population, and e $4+10 \%$ and e $4+20 \%$ correspond to the postulated decreases in tolerance values due to allele of the apoE genotype.

Although rotational acceleration thresholds are established from noncontact-induced experiments (e.g., [28]), studies have examined the importance of head contact to induce the necessary angular acceleration magnitudes. For example, Meaney et al., using computer models, emphasized head contact to develop inertial loading conditions to induce diffuse brain injuries in minor to moderate collisions; $\Delta \mathrm{V}$ of $74 \mathrm{~km} / \mathrm{h}$ was needed to exceed the tolerance for concussion and "yet higher velocities for mild to severe DAI" [29]. Their conclusions on the significance of head contact were supported by real-world epidemiological studies of Morris et al. [30]. Backaitis, from an analysis of 755 cases of AIS 3+ injuries in motor vehicle crashes, reported only one injury was associated with no contact [15]. In another analysis of 414 fatal cases of road users in Australia, McLean found no cases of brain injury in the absence of evidence of head 
impact [31]. Our-to-be-published review of cases from the CIREN database also shows head contact associated with brain injuries (with or without skull fracture) in motor vehicle occupants, thus, reinforcing the role of contactinduced dynamic force application to the human head.

\section{PENETRATING IMPACT}

The majority of studies in this area is focused on the military domain and used gelatin as the simulant for injury/wound quantification, typically determined as the residual deformation following projectile penetration $[1,2]$. In addition, the shape of the model is primarily confined to rectangular cross sections. Therefore, their applicability to human head trauma is limited. Recent tests from our laboratories have focused on civilian projectiles, used a more realistic brain simulant, and employed highfrequency pressure transducers coupled with very high-speed digital videography to capture the sequence of temporary cavities, and adopted a model better approximating the shape and boundary conditions of the head.

Briefly, two agents of a silicone dielectric gel, Sylgard 527 A and B were mixed and poured into a diameter globe. A hole in the center of the globe approximated the foramen magnum. A layer of neutral density reference lines was embedded in the "mid-sagittal plane" of the globe to monitor temporal movements of the projectile and gel material. Four pressure sensors were inserted into the globe through predrilled symmetrical holes. Two transducers were close to the entry, and two were close to the exit of the projectile. These pairs were referred to as entry- and exit-transducers for data interpretation. All transducers were approximately at the mid-height of the globe. They were inserted $3.5 \mathrm{~cm}$ from the outer surface of the globe so that all sensors were mutually orthogonal to each other. Nine-mm and 25caliber projectiles were discharged to ensure penetration at the mid-diameter of the globe. The test was photographed using a digital video camera at 20,000 frames/sec. A digital data acquisition system was used to capture the transducer signals at $308 \mathrm{kHz}$. A fresh globe was used for each test. Parallel tests were conducted by replacing the Sylgard gel with gelatin. Pressure data are summarized in table 4.

Table 4: Peak average pressures $(\mathrm{kPa})$ comparing responses from two brain simulants for two projectiles. Averages were computed from the two entry-and two exit-transducer sets.

\begin{tabular}{lcccc}
\hline \multicolumn{1}{c}{ Projectile } & \multicolumn{2}{c}{25 caliber } & \multicolumn{2}{c}{$9 \mathrm{~mm}$} \\
\hline Simulant & Entry-transducers & Exit-transducers & Entry-transducers & Exit-transducers \\
\hline Gelatin & 245 & 151 & 569 & 484 \\
\hline Sylgard gel & 179 & 242 & 645 & 630 \\
\hline
\end{tabular}


In general, results from both simulants indicated significantly higher energy and wounding power for the 9 -mm than the 25 -caliber projectile; this was determined by the formation and collapse of the temporary cavities and pressure distributions. The $9-\mathrm{mm}$ and 25 -caliber projectiles had entry velocities of 378 and $238 \mathrm{~m} / \mathrm{s}$. The Sylgard gel responded with higher changes in pressures than the gelatin (e.g., entry: 466 versus $324 \mathrm{kPa}$ ) for the 9-mm projectile, demonstrating its greater sensitivity. Because material properties of the gel are closer to the human brain, i.e., increasing dynamic modulus with increasing loading frequency, and because this simulant responded with more differentiable responses compared to the gelatin, the gel may be the most appropriate simulant for brain injury penetrating trauma studies. Temporal pressure distributions at various locations can be used to validate computer models aimed to delineate stress analysis-related variables for brain injury quantifications. Numerical models using the finite element technique are being pursued in our laboratories.

\section{ACKNOWLEDGEMENTS}

This study was supported in part by DTNH22-H-03-04117, PHC CDC R49 CCR 519614, and VA Medical Research.

References:

1. Yoganandan N, Pintar F. Biomechanics of penetrating trauma. CRC Review Biomed Eng 1997;25:485-501.

2. Yoganandan N, Pintar FA, Kumaresan S, et al. Dynamic analysis of penetrating trauma. J Trauma 1997;42:266-272.

3. Gurdjian ES, Webster JE, Lissner HR. Observations on the mechanism of brain concussion, contusion, and laceration. Surg Gynecol Obstet 1955;101:680-690.

4. Gurdjian ES, Lissner HR, Evans FG, et al. Intracranial pressure and acceleration accompanying head impacts in human cadavers. Surg Gynecol Obstet 1961;113:185-190.

5. Gurdjian ES, Schwan H. Management of skull fracture involving frontal sinus. Am J Surg 1932;95:22-32.

6. Messerer O. Uber Elasticitat und Festigkeit der Menschlichen Knochen. Stuttgart, Germany, 1880:79.

7. Evans FG, Lissner HR, Lebow M. The relation of energy, velocity, and acceleration to skull deformation and fracture. Surg Gynecol Obstet 1958;107:593-601.

8. Lissner HR, Lebow M, Evans FG. Experimental studies on the relation between acceleration and intracranial pressure changes in man. Surg Gynecol Obstet 1960;111:329338.

9. Holbourn AH. Mechanics of head injuries. Lancet 1943;2:438-441.

10. Gurdjian ES, Lissner HR, Patrick LM. Concussion-mechanism and pathology. Stapp Car Crash Conf., Los Angeles, CA, 1963:58-60. 
11. Society of Automotive Engineers. Human tolerance to impact conditions as related to motor vehcile design-J885. Warrendale, PA: SAE, 1980.

12. Versace J. A review of the severity index. Stapp Car Crash Conf. Coronado, CA, 1971:771-796.

13. Kleinberger M, Sun E, Eppinger R, et al. Development of improved injury criteria for the assessment of advanced automotive restraint systems. Washington, DC: NHTSA, 1998:115.

14.NHTSA. www.nhtsa.dot.gov [Department of Transportation]. October, 2003.

15. Backaitis SH. The head injury criterion. Head and neck injury criteria: a consensus workshop. Washington, DC: US Department of Transportation, 1981:175-177.

16. Eppinger RH. Discussion of injury criteria. Head and neck injury criteria: a consensus workshop. Washington, DC: US Department of Transportation, 1981:204-249.

17.Hackney JR, Kahane CJ, Quarles VR. The new car assessment program -- historical review and effect, 1994:75-89.

18. Kuppa S. Injury criteria for side impact dummies. Washington, DC: National Transportation Biomechanics Research Center, National Highway Saftey Administration, US DOT, 2004:67.

19.Lowenhielm P. Mathematical simulation of gliding contusions. J Biomech 1975;8:351356.

20.Gennarelli TA. The spectrum of traumatic axonal injury. Neuropathol Appl Neurobiol 1996;22:509-513.

21.Gennarelli TA, Meaney DF. Mechanisms of primary head injury. In Wilkins R, Rengachary S eds. Neurosurgery. 2nd ed. New York: McGraw Hill, 1996:2611-2621.

22. Gennarelli T, Thibault L, Adams J, et al. Diffuse axonal injury and traumatic coma in the primate. Ann Neurol 1982;12:564-574.

23. Gennarelli TA, Thibault LE. Biomechanics of acute subdural hematoma. J Trauma 1982;22:680-686.

24. Gennarelli TA, Adams JH, Graham D. Acceleration induced head injury in the monkey. Acta Neuropathology 1981;7:23-28.

25.AIS. The Abbreviated Injury Scale. Arlington Heights, IL: American Association for Automotive Medicine, 1990.

26. Gennarelli T, Pintar F, Yoganandan N. Biomechanical tolerances for diffuse brain injury and a hypothesis for genotypic variability in response to trauma. AAAM. Lisbon, Portugal, 2003.

27. Ommaya AK, Gennarelli TA. Cerebral concussion and traumatic unconsciousness. Correlation of experimental and clinical observations on blunt head injuries. Brain 1974;97:633-654.

28. Margulies SS, Thibault L. A proposed tolerance criterion for diffuse axonal injury in man. J, Biomechanics 1992;25:917-923.

29. Meaney D, Thibault L, Gennarelli T. Rotational brain injury tolerance criteria as a function of vehicle crash parameters. IRCOBI. Lyon, France, 1994.

30. Morris A, Hassan A, Mackay M, et al. Head injuries in lateral impact collisions. IRCOBI, 1993:41-52.

31. McLean AJ. Brain injury without head impact? In Bandak FB, Eppinger RH, Ommaya AK eds. Traumatic Brain injury. Larchmount, NY: Mary Ann Liebert Inc., 1996:45-49. 